\title{
Researching Vietnamese People in the Context of International Integration Today
}

\author{
Pham Cong Nhat* \\ University of Social Sciences and Humanities, VNU, Vietnam
}

*Corresponding Author: Pham Cong Nhat, University of Social Sciences and Humanities, VNU, Vietnam

\begin{abstract}
Researching and evaluating Vietnamese people appear quite early in ideological history in Vietnam. Through different periods, the study and evaluation of Vietnamese people has brought about different results reflecting research conditions and perceptions at each historical stage. Studying and evaluating Vietnamese people in the context of international integration today, besides positive results, there are also certain limitations and shortcomings, which require orientations not only clearly define the objectives, strategies and exchange of international cooperation, but also have to build a new and modern research method system that is not only suitable with the actual conditions of Vietnam but also must be consistent with the information rules and standards in human research and evaluation of most countries in the world.
\end{abstract}

Keywords: Vietnamese people, studying Vietnamese people, development resources, doi moi, international integration.

\section{INTRODUCTION}

People are the most precious capital (the most valuable asset) of each country in the development process. Therefore, the full research and evaluation of the characteristics of the role and power of each nation in different periods is very important. Because it is one of the bases that help the country to promote this valuable resource in the development process. Vietnam is in the process of innovation, implementing the cause of industrialization, modernization and international integration. Therefore, the research and evaluation of the role of the Vietnamese people in the current period is more important.It helps us to clearly identify Vietnamese people from different perspectives, from which we can propose important solutions to effectively promote Vietnamese human resources in the development process. This article, on the basis of the basics of the history of the study of Vietnamese people in history, proposed the requirements and solutions to study and evaluate more effectively Vietnamese people current international integration period.

\section{METHODS}

In this paper, we use common research methods such as history, logic, analysis, synthesis. In addition, we also use a number of interdisciplinary methods such as statistics, comparison and comparison to analyze clearly the similarities and differences in the development of Vietnamese people in the past and present. In this article we also use some data and results of the authors' studies and other research works (including authors and overseas research works) on people Vietnam to analyze and clarify the characteristics of Vietnamese people today.

\section{RESUlts}

\subsection{Some Research Results about Vietnamese People in Previous History}

Although it is a nation with a large land and a non-population, Vietnam is a country with a long history and culture. Due to the conditions of historical impact, the country of Vietnam has always been in a process of continuous struggle to build up and keep the country. It is the struggle that seems to be unbalanced between one side, the great natural power and one side of the small human force; between one side are powerful foreign powers (powerful in terms of both the number of people and the attached material conditions) with a small nation both in terms of physical and human resources. That has always motivated thinkers in Vietnamese history to study and understand the Vietnamese 
people affirming their advantages but not hesitate to point out the disadvantages with the aim of nothing more than promote the power of Vietnamese people in the construction and maintenance of their country. Right from the XIII century, Hung Dao Vuong Tran Quoc Tuan (1228-1300) in his famous "Hịch Tướng Sĩ" post pointed out that: Vietnam is a small nation, so it wants to win the events fighting against foreign invaders is nothing more than creating national unity. National unity will create the power for the Vietnamese people to cope with foreign forces, resolutely fight and win. It is the political ideology of "people do not divide" and "the whole country to contribute" against Tran Quoc Tuan's enemy as the foundation for building permanent army and all people's armed forces during the Tran dynasty [Nguyen Tai Thu, 1993; p.189]. In the XIV century, Nguyen Trai (13801422) in "Bình Ngô Đại Cáo" again mentioned the power of Vietnamese people. Opening this immortal work Nguyen Trai has affirmed the ability and strength of Vietnamese people as the owner of an independent sovereign country on par with the major countries in northern Vietnam:

"Like our Dai Viet nation from before;

Originally inherited from civilization for a long time;

River mountain and border have been identified;

The customs of the North and the South are also completely different; Since the Trieu, Dinh, Ly and Tran dynasties have built their independence;

Along with Han, Duong, Tong and Nguyen dynasties, each party established their dominance

Although strong and weak are different;

But every era appears heroes" [Nguyen Trai, 1976; pp.63-64].

According to Nguyen Trai, from the successful lesson of the Vietnamese people, a small, weak, exhausted nation, rare talents such as "morning star", "autumn leaves" but always confront and know how to handle the victory in the struggle with the great empires in the North such as: Tan, Han, Duong, Tong and and Minh is because Vietnamese people know how to create the power of great unity and thanks to this great unity block. which has made the motto "take strong victory", "take a lot of enemies" leads to victory in the great war wars. The strength of solidarity (solidarity between people and people, solidarity, national solidarity...) has helped the Vietnamese to win every war against the enemy as well as the summation of many thinkers before that.

General assessment, despite trying to delve into the character and nature of Vietnamese people in different contexts of history, it is influenced by the world view as well as class ideology (especially the world of idealistic and feudal ideology ...), the research results on Vietnamese people of Vietnamese thinkers through these periods are still scattered, not fully described about the characteristics and role of Vietnamese people.

Research and evaluation of Vietnamese people basically only started with the research works of researchers in and outside Vietnam from the first half of the nineteenth century (when there was the introduction and delivery Culture and methodology in scientific awareness of Western countries, especially France with Vietnam). Opening the Vietnamese cultural and human research movement in this period must include French researchers in Vietnam such as: Bell Combe with the book: "Bibliographie Annamique" (Thư mục An nam), (Paris, 1862); Barbié du Bocage with the book: "Bibliographie Annamite" (Thư mục An nam), (Paris, 1867); Cadière L.et Pelliot P. with the book: "Première etude sur Les soures Annamites de L'histoire d'Annam". BEFEO, Jullet - Septembre. 1904. Hanoi, Imp F.H. (Initial research on Annam's history through sources of Annam, Trinh Kim Chi, 2010; pp/.32-35).

Although the number as well as the authors of research works on Vietnamese people in this period is not much, but with a relatively new research approach (mainly using empirical methods instead of research methods) saving domestic tradition - speculation based on self-observing experience, so the results of research on Vietnamese people of French researchers in this period have created the initial touches in the description. Physical, psychological, mental and social characteristics of Vietnamese people. These research results are also very important prerequisites for the study of Vietnamese people in the next periods.

In the early twentieth century with the Duy Tan and Dong Du movements, for the first time, Vietnamese people were compared with East Asians and Westerners. Since then, along with the 
acquisition and development of specialized sciences, knowledge of people in general and Vietnamese people in particular, has been accumulated more and more richly. However, that knowledge is generally still scattered in separate scientific disciplines such as: Philosophy and Culture, History and Archeology, Medicine and Ethnology, Sociology and Psychology, Ethics and Anthropology, etc. The research results on Vietnamese people in this period are also associated with the names of many domestic researchers, especially among them are the authors like Tran Trong Kim, Dao Duy Anh, Nguyen Van Vinh.... With the published research works of the two men, it is the first time in history that: Vietnamese people have been described and evaluated in many aspects from residence characteristics to structural characteristics. Anatomy, physiology, psychology and society. Especially, for the first time, they also pointed out the homogeneity and difference of Vietnamese people not only in terms of gender but also in different regions, the development and change of psychological structure of Vietnamese people through the ages.

In the book: "Brief history of Vietnam", author Tran Trong Kim describes the characteristics of Vietnamese people as follows: "Vietnamese people have two toes that are tied together, so Tàu (Chinese) is called "Giao Chi" after many changes in life and into Vietnamese people today" [Tran Trong Kim, 1999; p.13].

In terms of anthropological and morphological characteristics, Tran Trong Kim said: "Vietnamese people belong to the yellow skin type, but those who have to go to work are often sun-drenched, so the skin is dark and dark. Leisurely, staying indoors, white skin is like ivory color. The figure is lower than the Chinese (Chinese), who roll over people, not fat. On the other hand, the bones and the bones, the slightly flat looks, the forehead is high and wide, the eyes are slightly slanted to the tail, the cheeks are high, the nose is slightly tanned, the lips are thick, the teeth are big and blackened. The beard is sparse, but the hair is more and more long, black and slightly hard. Take a gentle stance and watch for a firm grip. Clothes are long, men are chignon and bandanas, wearing long sleeves, sleeves are tight, pants are wide. Women in North Vietnam and northern Central Vietnam wear towels. Women in urban areas wear pants and rural areas wear skirts. Women in central and southern Vietnam wear pants and tufts, not wearing a scarf at all" [Tran Trong Kim, 1999; p.14].

Describing psychological and cognitive characteristics, he writes: "Vietnamese people have good qualities and bad characteristics. General knowledge is lucid, learns quickly and skillfully, many people are bright, long-term, have a fondness for learning, respect for the study of politeness, love for morality to take the cause, meaning, ceremony, position, credit, do 5 directors often for accommodation. However, there is still the wisdom, sometimes when there is insidiousness and the mockery. Often shy and eager to peace, but having gone out to battle, there is also courage and discipline. Women often work hard and are good, skillful, skillful, able to do all kinds of things, but take the path of religion as the most important, all the way to the husband, to raise the children, often keep the very noble qualities: meaning, need, save. Vietnamese from North to South, following a custom, speaking in a language, holding a true memory are the identity of a nation from the beginning of the country to the end of the country "[Tran Trong Kim, 1999; p.13].

Also with a new research approach to Vietnamese people, the author Dao Duy Anh in the book "Vietnam culture of history" has described the Vietnamese people as follows: "Considering the nature of Vietnamese people day Now, we see that Vietnamese people are short-head (only 28.2), I am low (1m58), small limbs, bone face, high right, black and slightly slanted eyes, slightly flat nose, slightly lips thick, dark and slightly hard hair, stiff and sparse beards, smooth and firm movements. However, when compared to the North Vietnam and the north of Central Vietnam, there are strong and tall figures (1m59; the inner ones are weak and lower $(1 \mathrm{~m} 57)$. That difference is due to being influenced by the terrain and climate that is generated. However, Vietnamese people are still a pure category if we consider living and culture, it becomes even more obvious. In terms of spirituality, Vietnamese people are generally smart, but very few people have brilliant and extraordinary intelligence. The power of memory is very prosperous, but more artistic than the scientific position, more intuitive than logic. The majority of people are eager to learn, but prefer literary literature rather than realism, preferring to form and form rather than active thought. The imaginative brain is often delayed by the brain, so the Vietnamese people are less dreamy, but the judgment is often very practical. The hardest

\footnotetext{
"'Giao Chi" is the name of a part of Vietnamese territory in history, from the time of Hung Vuong to the Northern domination periods.
} 
work is the people in the North, so few people can catch up. The feeling is a bit slow but good at pain, suffering and patience. The temperament is also a bit shallow, insecure and frustrating, or bragging on the outside, fanciful and like to gamble. Often shy and peaceful, but enlightenment is also known to sacrifice for great meaning. The brain composes little, but imitation, adaptation and tolerance are very talented. Vietnamese people are very respectful of the religious ceremony, but they also have a great brain, or a sneer. It is a brief description of the most common spiritual characteristics of the Vietnamese people, and also has a slightly different origin from the caveman, which changes slightly, also due to the history and the social state that gradually fades, so we should not consider them as immutable, immutable"[Dao Duy Anh, 2000; pp.22-24].

In his works, author Nguyen Van Vinh discusses many bad habits often found in Vietnamese people at that time such as dependency, cheating, eating habits into oral debts, selling credits. Suspicion, illusory behavior, low borrowing, creativity, chance of chiseling stubby water, habits "all laugh", bad gambling... [Nguyên Thi Le Ha, 2010]

Thus, right from the late nineteenth century and early twentieth century, Vietnamese people have been paying attention to research and presentation of these results by thinkers. However, due to the age factor (late nineteenth and early twentieth centuries), most researchers have not been able to access much with the interdisciplinary and modern scientific knowledge, so the research results on Vietnamese people in general are not comprehensive and incomplete since then, the requirements of studying and evaluating Vietnamese people in the new context need to be more complete and comprehensive.

\subsection{New Features in the Study of Vietnamese People Today}

Since Vietnam was born (1945) until now, the study of Vietnamese people has many new features in terms of approach to research subjects, research methods and achieved results.

In terms of approach to research subjects, as the development and subdivision of sciences is becoming more and more profound, the deep understanding and research of Vietnamese people has been implemented in many other ways together. In addition to the traditional sciences such as Philosophy, History or Cultural Studies, many new sciences have appeared in-depth study, research and evaluation of Vietnamese people, most notably still some subjects such as Psychology, Medicine... Especially, before the requirements of international innovation and integration of Vietnam, there have appeared a number of new sciences that are interested in researching and evaluating Vietnamese people. Men like: Sociology, Demography, Anthropology, etc.

Regarding research methods, because there are many approaches to research, the methods of research and evaluation of Vietnamese people are no longer limited by some traditional research methods as often seen as before. In contrast, the current system of research methods of Vietnamese people is quite diverse and rich. In addition to a number of common research methods, which are widely used by most scientific disciplines such as history, logic, analysis, and synthesis, there are also specialized methods that are suitable for research subjects of different sciences. A new feature in the use of Vietnamese research methods today is the trend of using more and more popular methods of empirical research such as sociological investigations, psychological tests, gods. sutra and bio-testing methods to obtain research results assessing Vietnamese people more comprehensively, etc.

With the use of diverse research methods, especially updating more and more modern research methods, focusing on experimental methods, etc., it was initially created similar research results. Comprehensive confrontation about Vietnamese people today. In this article, we can initially state some outstanding research results about Vietnamese people today such as:

Firstly, the number of authors and research works at home and abroad about Vietnamese people is increasingly crowded under different research angles. Typical of these must include the authors and in-depth research and evaluation of Vietnamese people in recent years such as the group of authors Le Nam Tra, Tran Van Dan, Tran Dinh Long... [1996], with the project "Initial results of studying some Vietnamese biological indicators" through the basic survey project, the results of general assessment of young morphological indicators have been given initially. children, adults and functions, immunity, hematology and biochemistry ... of Vietnamese people today [Le Nam Tra, 1996]; Author Duong Nghiep Chi with studies on physical and physical conditions of Vietnamese people (Duong Nghiep Chi, 2003); Author Pham Minh Hac with the psychological and physical studies of the people in the 
period of accelerating industrialization [Pham Minh Hac, 2001]; Nguyen Van Huyen with research works on Vietnamese people from the perspective of learning culture [Nguyen Van Huyen, 2002]; Author Nguyen Ngoc Ha with studies on Vietnamese people's lifestyle thinking in the process of international integration [Nguyen Ngoc Ha, 2012]; Author Vuong Tri Nhan with studies on Vietnamese psychology [Vuong Tri Nhan, 2016], etc.

Secondly, the information on research findings about Vietnamese people is relatively more complete and has been mentioned and evaluated under the perspective of many different sciences: philosophy, culture, main treatment, economics, psychology, neurophysiology, biometrics, anthropology, etc. A diverse research approach, the results of research on Vietnamese people are not only by economic reasoning. Pure experience but also the result of collecting from many scientific evidence, especially evidence in experimental science. It can be said that, synthesizing the results of the current research has shown us the multi-dimensional picture of Vietnamese people from a scientific perspective. Vietnamese people today are both a part of Vietnamese people inherited in the past but also a part (very important) of the Vietnamese people who are eager to innovate, create and expand society enter the world.

Thirdly, because there is more evidence, the information collected from different dimensions should result in research and evaluation of the advantages and disadvantages of Vietnamese people presented more fully and objectively. For example, current human studies in Vietnam are not only at the level of general science but also in depth such as: mental health, psychosocial, gender, region or divide into ethnic communities, etc. Along with promoting domestic studies, the Government and the State of Vietnam also allow domestic organizations and individuals to coordinate with international organizations such as the World Bank (WB) and Development Organization. United Nations (UNDP)... to research and evaluate to have a more comprehensive view of Vietnamese people today.

Fourth, some assessments about Vietnamese people today:

Evaluation of President Ho Chi Minh. Ho Chi Minh is the leader of the Vietnamese people. He is the founder of the Communist Party of Vietnam and also the birth of the Democratic Republic of Vietnam (current Socialist Republic of Vietnam). Ho Chi Minh also had warnings about bad habits in the cadre class as he mentioned in his very famous book: "Sửa đổi lối làm việc" (Modifying the way of working (1947). [Quang Minh, 2012] According to him, the Father of all defects is individualism. The greed, laziness, flower, faction, locality, ham, prestige, bureaucracy, bureaucracy, far away from the masses, narrow-minded, formal, way of working on the desk, indiscipline selfishness, selfishness and many other bad qualities from there. [Tran Quang Trung, 2012]

Evaluation of Professor Tran Ngoc Them. According to Professor Tran Ngoc Them in "Finding about Vietnamese cultural identity", he pointed out that for Vietnamese people, when facing big difficulties, the risks threaten the survival of the whole community. What emerges will be solidarity and collectivity; but when that risk is over, it is possible that the private and the factionalism and the local mind will emerge. [Tran Ngoc Them, 2001; 198]. In communication, when you find yourself standing in a familiar community, your communication likes to emerge, and when you get out of the community, stand in front of strangers, shyness will overwhelm. [Tran Ngoc Them, 2001; pp.278279] The duality of Vietnamese people often works well in extremely difficult circumstances, one is lost (typically in the war), while in peace building, in the process of industrialization and urbanization It is regrettable that often the reverse side of this duality is outstanding.

Vietnamese people have a moderate philosophy, "very hard to grind", "just enough to use" and not have the habit of appreciating time, consider the time as "rubber", [Tran Ngoc Them, 2001; p.278] because of that. I have to get rich. Only when I find myself being inferior to the people around me, will I try, but as soon as I see myself as everyone else, I will work in moderation. The style of doing this is completely unsuitable for urban life. [Tran Ngoc Them, 2001; pp.278-279]

Evaluation of the researcher Vurong Tri Nhan. According to Vuong Tri Nhan, many Vietnamese people have their own inferiority complex from which to create self-conscious psychology or "there is no part better than people but I have another". Psychology and way of thinking of Vietnamese people are small and shallow; Vietnamese people have a bad habit of being inaccurate in everything, lack of science, lack of research, living very innocently.[Vương Tri Nhan, 2013.] Vietnamese people are arbitrary, lack the ability to cooperate, are less likely to put themselves in the position of others, 
[Vương Tri Nhan, 2006] arrogant, "find yourself a center". [Vương Tri Nhan, 2013.] Vietnamese people also lack the experience of relations with the outside world, accustomed to shrinking life, with little desire to go to the world, to understand the world. However, Vietnamese people also have the advantage of quick adaptation, quick learning but superficial, easy-going, not receiving in the depth of culture. [Vương Tri Nhan, 2009]

Vietnamese people are doing business by thinking of war "despite the law as long as they are able to work; only take care of efficiency, and the price of it is not needed" [Vương Tri Nhan, 2009]. "The Vietnamese people have a lot of bad things, and it is a greed and time to reunite" [Vương Tri Nhan, 2013]. Vietnamese people are instinctive and spontaneous, less rational, thinking, and vision of Vietnamese people is short-term, only know in the short term and present. [Hoang Luc, 2013]

Vietnamese people have heavy minds, psychology carries many illusions, just like being praised by others. Even when other people criticize themselves, Vietnamese people find it hard to hear. [Vương Tri Nhan, 2013] Vietnamese people have little need to counteract, often devoid of reasons to fight against the cause, thus making mistakes, bad habits deeper into social life. [Hoang Luc, 2013]

The independence of Vietnamese people in thinking, lifestyle, behavior... is not high. [Vương Tri Nhan, 2009]. All these bad habits will hinder the development of the Vietnamese people. [Vương Tri Nhan, 2013].

Evaluation of Professor Nguyen Lan Dung. According to Professor Nguyen Lan Dung, many Vietnamese people are lowering their position, anything to ask for, to ask for, to dare not publicize the wrong actions of those who have the right and authority I became vile, submissive, ignoring all wrongs, all bad developments in society due to the lack of democratic social life made the bad not only to be named. In addition, there are many people suffering from "crazy status" disease. This is associated with a lack of exemplary and degrading state officials at all levels due to the lack of trust in the state apparatus and little use of talented people. Vietnamese people do not understand the positive side of the market economy, but they are badly affected by the market economy. Greed repels personality, worsens social relationships. Besides that is the proficiency, qualifications, especially state officials. Many Vietnamese people now consider money more than education. In summary, according to him, there are 5 most common bad things in Vietnam today are: greedy money, honor, despise honor, emotionless and cowardly, disregarding the meaning of "people" [Nguyen Lan Dung, 2013], etc...

\subsection{Some Limitations on Studying Vietnamese People Today}

In addition to the achieved results, the study of Vietnamese people in the context of international integration is still limited such as:

- The research approach is still outdated: as the research area has not been zoned, the research methods are backward, leading to difficult research results to ensure scientific reliability. For example, any research shows that Vietnamese people are diligent and intelligent, but they do not indicate the bases to prove the intelligent diligence of Vietnamese people. It is a fact that many of the current conclusions about Vietnamese people are based on the conclusions of previous unproven or scientifically proven previous studies that are convincing in studies. This is not high.

- Lack of association in research. This is a reality in the current picture of scientific research activities in Vietnam, including the current situation of research on Vietnamese people in particular. Of course, in recent years, with the investment and strong research orientation of the State, it has contributed to overcoming a part of the fragmentation in the study of Vietnamese people, but on a wide scale, the research works This research also has a lot of spontaneity, so the research results are often overlapping, contradictory and supporting each other in the same research direction.

- Also influenced by political prejudices in research. That is to be influenced by the opinions and political views that have been formed, before realizing the facts related to the research object. Of course, in scientific research there needs to be a political perspective and it is normal and necessary for a certain scientist to stand on some political standpoint, but if it turns into a political prejudice, especially that prejudice is formed from misconceptions about political issues that existed before, it becomes obstacles to scientific awareness, or create scientific research results. Learning deviance, lack of objectivity. For example, there was a period of time due to wrong political prejudices about 
the country development model, so there was a period when Vietnamese researchers painted a new model of Vietnamese people, also called "people." new socialism "with exaggerated qualities or a combination of characteristics that are alien to the real qualities of Vietnamese people like" people with a patriotism of passionate socialism combined smoothly with the spirit of innocent proletariat "(Vietnamese Communist Party, 1976: 65), etc. Therefore, want to obtain objective research results in researching the current Vietnamese people. Many limitations must be overcome, including restrictions on political prejudice in research.

Has not built up a team of experts (strong research team) and research scale capable of exchanging and cooperating with researchers at home and abroad. This is one of the major limitations in studying Vietnamese people in the current international integration period in Vietnam. Since strong research groups cannot be created, research results on Vietnamese people are often discrete, spontaneous and sometimes overlapping.

\subsection{Some Solutions to Research Vietnamese People in the Current International Integration Period}

International integration is the process of joining, linking, and cooperating of a country with many other countries in the region or the world. The content of participating in international integration of each country can be one or more fields, from politics and economy to culture and social spiritual life. Participating in international integration is considered one of the important contents of Vietnam in the current renovation process. The process of innovation and international integration forces Vietnam to change the way it operates and interacts in many fields including the field of scientific research activities. Therefore, the research and evaluation of Vietnamese people today must also be in the context, the context of the domination of international integration process. Therefore, the study and assessment of Vietnamese people in the current new context does not merely indicate the advantages or disadvantages but the most important point is to build a standard value system of new Vietnamese people with many constituent and intertwined elements as confirmed in terms of views expressed in the document of the 12th National Congress of the Communist Party of Vietnam: "Building people Vietnam develops comprehensively. Perfecting Vietnamese cultural and human values standards, creating an environment and conditions for development of personality, morality, intelligence, creative, physical, soul, social responsibility, citizen obligations, a sense of law compliance. Create a strong change in awareness, a sense of respect for the law, all Vietnamese people have a deep understanding, pride, honor of national history and culture. To consolidate and build a standard value system of Vietnamese people in the period of industrialization, modernization and international integration. Affirm, honor the right, the good, the positive, the noble; replication of high, beautiful and human values. Fight critically, repel bad, evil, lowly, backward; opposing wrong views and negative behaviors adversely affecting the construction of culture and alienating people. There is a solution to prevent and repel the social moral degradation, overcome the limitations of Vietnamese people" [Vietnam Communist Party, 2016: 126-127].

The departure of the context, conditions and new perspectives as analyzed above shows that the research and assessment of Vietnamese people in the current international integration period should pay attention to the following solutions:

Firstly, it is necessary to redefine the goal of studying Vietnamese people in accordance with the national goal of innovation and international integration. The basis for determining the research objectives of Vietnamese people today is the context of innovation, industrialization, modernization and international integration. Therefore, the Vietnamese human strategy is aimed at and towards the results to serve the national development process in the process of innovation, industrialization, modernization and international integration. We believe that the objective of researching and evaluating Vietnamese people today is nothing more than to identify the strong and weak characteristics of Vietnamese people in the context of international integration as a source. Vietnam's most important force in the process of innovation, industrialization, modernization and international integration.

Secondly, build new standards in line with international practices in research and evaluation of Vietnamese people today. The new standard in the research and evaluation of Vietnamese people here is not only the identification of research contents but also other important factors that must be consistent with research methods, paying special attention to modern methods. in researching and 
evaluating Vietnamese people. In particular, one of the practices in human research in the world needs to be strictly applied in Vietnam today to ensure that the objective principle in human research can be assessed. Full of advantages (advantages to be promoted) and limited (obstacles to overcome) of Vietnamese people in the current international integration period.

Thirdly, strengthening the exchange and cooperation process (domestic and international) in the research and evaluation of Vietnamese people today. This is a trend and a mandatory requirement for the research and evaluation of Vietnamese people in the current international integration period. This requirement can be concretized by developing regulations in research, building specific mechanisms to facilitate organizations and scientists to exchange research cooperation between parties easily.

Fourthly, it is necessary to build an appropriate mechanism, creating open views in line with international practices in the study of Vietnamese people today. In order to do so, there should be a suitable mechanism for domestic and foreign scientists to participate in research. At the same time, it is necessary to accept different views that are not even compatible with each other in researching and evaluating Vietnamese people. In order to obtain objective research results, it is necessary to establish a democratic environment in scientific research, so it is necessary to avoid stigma and hat or raise political views on research results that do not match Combining Vietnamese people in the current international integration period.

\section{CONCLUSION}

History of research and evaluation of Vietnamese people appeared quite early. Through different historical periods, research and evaluation of Vietnamese people has resulted in different results in contrast to research conditions and perceptions at each historical stage. In this new period, the research and assessment of Vietnamese people besides important achievements also reveals limitations, especially in the context of innovation and international integration today. Therefore, the research and assessment of Vietnamese people in the current international integration period requires not only to define the objectives, strategies and exchange of international cooperation but also to build a system of methods. New and modern researches are not only suitable with the actual conditions of Vietnam but also in accordance with the practices and standards in research and evaluation of people of most countries in the world. Identifying and effectively applying solutions to research and assess Vietnamese people in the current international integration period not only makes us understand more about Vietnamese people but also the results of this research will be one of the premise to promote the overall development of Vietnam in the current renovation process

\section{REFERENCES}

[1] Nguyen Lan Dung, "A lot of Vietnamese people have money, emotionless, cowardly...", Tien Phong electronic, updated on May 13, 2013.

[2] Communist Party of Vietnam, 1976, Documents of the 4 th National Congress of Representatives. The Truth Publishing House, Hanoi

[3] Communist Party of Vietnam, 2016, Documents of the 12th National Congress. National Political Publishing House, Hanoi

[4] Dao Duy Anh, 2000, Vietnam cultural history, Publishers Association Writers

[5] Mark and Geography, 1995, Complete set. Publishing House, National Politics, Hanoi.

[6] Trinh kim Chi, 2010, "The Vietnam works under French colonial rule". Vietnam Library Journal No. 2 (22).

[7] Duong Nghiep Chi (editor, 2003), Physical condition of Vietnamese people from 6 to 20 years old (Time of 2001). Publisher. Sports, Hanoi.

[8] Tran Trong Kim, 1999, Vietnam uses strategy. Publisher. Information Culture, Hanoi

[9] Nguyen Thi Le Ha, 2010, The contributions of Nguyen Van Vinh with the development of Vietnamese newspapers and the spread of the Vietnamese script. Nghe An Culture Newspaper, updated on September 13,2010

[10] Nguyen Ngoc Ha, 2012, "The characteristics of thinking and lifestyle of Vietnamese people today and the problems posed before the requirements of innovation and international integration". Code project Code: KX.03.07/06-10 (Under the key State-level Science and Technology Program KX.03/06-10 "Building people and developing Vietnamese culture in the process of innovation and international integration").

[11] Pham Minh Hac, 2001, Researching people and human resources into industrialization and modernization. Publisher. National Politics, Hanoi. 
[12] Nguyen Van Huyen, 2002, Some issues of social philosophy and human development. National Political Publishing House, Hanoi

[13] Hoang Luc, "3 questions of Mr. Vuong Tri Nhan help young people avoid" cheating car stains", Vietnam Education Newspaper electronic version, updated on June 6, 2013

[14] Quang Minh, Studying the work "Modifying the way of working" by President Ho Chi Minh, Nghe An Provincial Fatherland Front, updated on September 18, 2012

[15] Vuong Tri Nhan, 2016, Modern psychological injuries: Arguments. Publisher. Writers' Association, Hanoi.

[16] Vuong Tri Nhan, "The illness and greed of Vietnamese people cannot be cured". Vietnam Education Newspaper. Updated June 5, 2013]

[17] Vuong Tri Nhan, "Bad habits of Vietnamese people in only 300 pages, enough?". Dan Tri electronic newspaper. September 21, 2006. Updated September 21, 2006]

[18] Vuong Tri Nhan, "Improve living standards to adapt and develop". VnEconomy, updated on January 29, 2009

[19] Tran Ngoc Them, 2001, Finding Vietnamese cultural identity. Publishing House. Ho Chi Minh City.

[20] Nguyen Tai Thu (editor, 1993), History of Vietnamese thought. Episode I. Publisher. Social Science, Hanoi.

[21] Le Nam Tra (editor, 1996), "Initial results of studying some Vietnamese biological indicators", Proceedings of the Conference on Vietnamese biological indicators held in Truong Dai Study medicine in Hanoi on 14-15 May (Basic survey project). Publisher. Hanoi medicine.

[22] Nguyen Trai (full set), 1976, Translation of Social Science Publishing House, Hanoi.

[23] Tran Quang Trung, "Four principles of self-criticism and criticism according to Ho Chi Minh's Thought". Electronic portal of Ho Chi Minh Mausoleum. Updated on November 22, 2012]

\section{AUTHOR'S BIOGRAPHY}

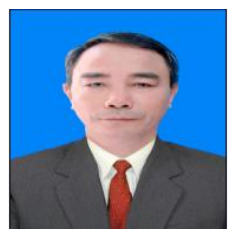

Pham Cong Nhat, Associate Professor, born in 1963 in Vietnam, Doctor of Philosophy, Faculty of Philosophy, University of Social Sciences and Humanities (USSH), Vietnam National University, Hanoi (VNU), Vietnam; Areas of study: culture, education, religion, human development and society, environmental ecology and sustainable development.

Citation: Pham Cong Nhat. " Researching Vietnamese People in the Context of International Integration Today". International Journal of Humanities Social Sciences and Education (IJHSSE), vol 6, no. 6, 2019, pp. 75-83. doi: http://dx.doi.org/10.20431/2349-0381.0506009.

Copyright: () 2019 Authors. This is an open-access article distributed under the terms of the Creative Commons Attribution License, which permits unrestricted use, distribution, and reproduction in any medium, provided the original author and source are credited. 